\title{
Las formas asociativas de la agricultura familiar en el desarrollo rural argentino de las últimas décadas (1990-2014)
}

\author{
Mario Lattuada, María Elena Nogueira y Marcos Urcola
}

\section{RESUMEN}

El asociativismo en el medio rural ha sido destacado históricamente como un factor que contribuyó al desarrollo de los pequeños y medianos productores agropecuarios. Desde la década de 1990 hasta la actualidad se observa una intensificación del pluralismo asociativo argentino en favor de los sectores de la agricultura familiar, con el surgimiento de cientos de nuevas asociaciones autogeneradas o promovidas por programas de desarrollo rural públicos y privados, y que a pesar de caracterizarse por la actividad cooperativa de sus integrantes no han adoptado esa forma jurídica tradicional. El objetivo de este trabajo consiste en delimitar una serie de nociones que permitan delimitar ese vasto y diversificado universo de asociaciones que identificamos como Asociaciones Económicas de la Agricultura Familiar (AEAF), construyendo, para ello, una serie de tipos ideales con el fin de proponer una herramienta para el abordaje empírico de su estudio en diferentes realidades locales, nacionales y regionales.

PALABRAS CLAVE: Asociativismo, agricultura familiar, desarrollo rural, Argentina.

CLAVES ECONLIT: Q120, Q130, Q180.

Cómo citar este artículo: LATTUADA, M., NOGUEIRA, M.E. \& URCOLA, M. (2015): "Las formas asociativas de la agricultura familiar en el desarrollo rural argentino de las últimas décadas (19902014)", CIRIEC-España, Revista de Economía Pública, Social y Cooperativa, 84, 195-228.

Correspondencia: Dr. Mario Lattuada, Investigador Principal del Consejo Nacional de Investigaciones Científicas y Técnicas (CONICET), Facultad de Humanidades y Artes de la Universidad Nacional de Rosario (Santa Fe, Argentina) y Universidad Abierta Interamericana (Argentina), E-mail: mjlattuada@gmail.com; Dra. María Elena Nogueira, Investigadora Asistente del CONICET, Facultad de Ciencia Política y Relaciones Internacionales de la Universidad Nacional de Rosario, E-mail: mariaelenanogueira@gmail.com; y Dr. Marcos Urcola, Investigador Adjunto del CONICET, Facultad de Ciencia Política y Relaciones Internacionales de la Universidad Nacional de Rosario, E-mail: murcola@hotmail.com. 


\section{Les formes associatives de l'agriculture familiale dans le développement rural argentin des dernières décennies (1990-2014)}

RÉSUMÉ : Les associations dans le milieu rural se sont imposées historiquement comme facteur ayant contribué au développement des petits et moyens agriculteurs et éleveurs. Depuis les années 1990 jusqu'à aujourd'hui, on observe une intensification du pluralisme associatif argentin en faveur des secteurs de l'agriculture familiale, avec l'apparition de centaines de nouvelles associations autogénérées ou promues par des programmes de développement rural publics et privés, qui, même si elles sont caractérisées par l'activité coopérative de leurs membres, n'ont pas adopté cette forme juridique traditionnelle. Ce travail vise à déterminer une série de notions permettant de délimiter ce vaste et divers milieu d'associations identifiées comme Associations Économiques de l'Agriculture Familiale (AEAF), en établissant, pour cela, une série de types idéaux pour proposer un outil d'analyse empirique de leur étude sur différentes réalités locales, nationales et régionales.

MOTS CLÉ : Associations, agriculture familiale, développement rural, Argentine.

\section{Types of family farm association in the rural development of Argentina in recent decades (1990-2014)}

ABSTRACT: Associations in rural areas have traditionally been pointed to as a factor that contributes to the development of small and medium-sized farming. From 1990 to the present, the number of associations in Argentina has multiplied among family farms. Hundreds of new associative partnerships have emerged, self-generated or promoted by public or private rural development programs, but although they are characterized by the cooperative activity of their members, they have not adopted this traditional legal form. The objective of this paper is to outline a set of notions that define the vast and diverse universe of associations identified as Economic Associations of Family Farms (AEAF) by constructing a series of ideal types, in order to propose a tool for an empirical approach to their study in different local, national and regional situations.

KEY WORDS: Associations, family farms, rural development, Argentina. 


\section{1.- Introducción}

El tema del asociacionismo en el medio rural ha sido destacado históricamente como un factor que contribuye al desarrollo de los pequeños y medianos productores agropecuarios, especialmente de aquellos que tienen menor acceso o disponibilidad de recursos económicos y productivos. Esta concepción, tradicionalmente acotada a las formas jurídicas cooperativas, se ha ampliado en cuanto a sus alcances, y fortalecido teóricamente a partir de los estudios académicos sobre capital social (Bourdieu, 1980, Putman, 1993, Woolcock, 1998, Coleman, 2000, Lin, 2001)1 así como también por los enfoques económicos neoinstitucionalistas (North, 1995) que ponen énfasis en la importancia de las organizaciones y las instituciones para el desarrollo. ${ }^{2}$

La rápida incorporación y difusión por parte de los organismos de financiamiento internacional y las agencias de desarrollo de esta concepción marcaron las estrategias de los programas de desarrollo rural en Latinoamérica en general y en la Argentina en particular durante las últimas tres décadas. ${ }^{3}$ Estos programas han promovido sistemáticamente metodologías de intervención grupales para brindar asistencia técnica, capacitación y financiamiento con el objeto de construir proyectos asociativos de diferente tipo que integren a productores y población rural vulnerable para mejorar sus condiciones de vida y sus capacidades de negociación y participación. El universo de grupos generados y de asociaciones creadas con el fin de recibir los beneficios de estos programas desde la década de 1990 hasta la actualidad ha sido significativo en cuanto a su número, heterogéneo respecto de su composición y grados de desarrollo y diferencial en materia de resultados.

Estas asociaciones que no están formalmente constituidas como cooperativas se han caracterizado por integrar a pequeños y medianos productores rurales que disponen de recursos productivos y financieros limitados y que llevan adelante la producción a partir de su propio trabajo o de la ges-

1.- El capital social puede ser interpretado como una red de relaciones sociales más o menos institucionalizadas y con cierta permanencia en el tiempo (Bourdieu, 1980) en la que ciertos valores y normas informales comunes a los miembros de un grupo (Putnam, 1993) refuerzan la incorporación y práctica de actitudes de confianza y comportamientos de reciprocidad y de cooperación, las que enraizadas en una sociedad (Lin, 2001) contribuyen a estructurar sus relaciones sociales posibilitando la colaboración de sus miembros para beneficio del conjunto de la comunidad (Woolcock, 1998). Este conjunto de valores, normas, actitudes y redes entre personas y organizaciones en una comunidad es considerado un factor influyente en el desarrollo económico, el desempeño de las instituciones democráticas (Putnam, 1993) y, por lo tanto, relevante para diseñar programas orientados a promover la participación social y superar la pobreza.

2.- Surge con claridad la relación del concepto de capital social con las proposiciones neoinstitucionalistas respecto de la sociedad que regula los comportamientos y relaciones humanas a partir de las instituciones, es decir, normas y reglas restrictivas formales (leyes, reglamentos, programas) e informales (ideas, creencias, valores, actitudes) que integran su cultura y que organizan la interacción de los actores sociales quienes se expresan a través de sus organizaciones, entendidas como grupos de individuos unidos por algún objetivo común para realizar actividades de utilidad para el conjunto. Las instituciones afectan a través de sus incentivos, oportunidades y restricciones las acciones de los agentes y en el largo plazo el desarrollo de los territorios y países (North, 1995).

3.- Véase BID (2001) y Banco Mundial (2001) entre numerosos documentos de estas instituciones que comenzaron a incorporar el tema del capital social y el desarrollo a partir del año 1998. 
tión directa de los predios con la colaboración de mano de obra familiar o de un reducido número de asalariados. También se integran en ellas grupos vulnerables de la población rural (trabajadores sin tierras, personas sub-ocupadas, artesanos, poblaciones aborígenes, etc.), que sólo de manera marginal se asociaban a las cooperativas formales.

El objetivo de este trabajo consiste en delimitar una serie de conceptos y nociones que permitan conocer con mayor profundidad ese vasto y diversificado universo de asociaciones que identificamos como Asociaciones Económicas de la Agricultura Familiar (AEAF) para generar una herramienta que permita el abordaje empírico de su estudio en diferentes realidades locales, nacionales y regionales.

El enfoque adopta un sesgo intencional poniendo especial interés en aquellas asociaciones que se constituyen como asociaciones económicas de la agricultura familiar, que generan agregado de valor y que a pesar de caracterizarse por la actividad cooperativa de sus integrantes no han adoptado esa forma jurídica tradicional para formalizar sus organizaciones.

En una primera instancia, el artículo sitúa al lector en el contexto nacional argentino señalando algunos datos demográficos, económicos, sectoriales agropecuarios y de la agricultura familiar, para luego describir el proceso de gestación y consolidación de las asociaciones rurales de la agricultura familiar en el país durante las últimas tres décadas. En una segunda instancia, se inicia un recorrido teórico a través de una serie de nociones y conceptos que permiten definir los aspectos que caracterizan a las AEAF y construir una serie de tipos ideales ${ }^{4}$ con el objeto de proponer una sistematización de la heterogeneidad de experiencias presentes en los territorios rurales. Por último, se presentan algunas reflexiones finales en torno a las condiciones favorables que presentan este tipo de asociaciones para transformarse en agentes de desarrollo e inclusión social en los territorios rurales.

4.- Como es sabido, el concepto tipo ideal acuñado por Max Weber, se elabora como un recurso metodológico que permite una tipificación conceptual del fenómeno o sujeto social en estudio y se construye con elementos provenientes de la realidad pero que no la describen, sino que sirven como herramientas teóricas para la contrastación empírica (Weber, 1996). Como bien indica Peón et al. (1993), en el sentido que otorga Weber a la imputación causal, el tipo ideal no se agota en el momento explicativo; supone, además, un momento previo de gran importancia, el de la comprensión. Por este motivo, este recurso metodológico es definido tanto enfatizando las características de "utopía inhallable empíricamente en la realidad" como, asimismo, "guía heurística", una "herramienta de investigación y fuente de hipótesis" (Peón et al., 1993:15). Esto último resulta de gran utilidad para este trabajo. 


\section{2.- EI contexto argentino}

Argentina es un país federal integrado por 23 provincias más el territorio de la ciudad autónoma de Buenos Aires, con una extensión de $2.780 .403 \mathrm{~km}^{2}$, con una baja densidad poblacional de 14,4 habitantes por $\mathrm{km}^{2}$ y una reducida tasa de crecimiento demográfico (1,1\% anual) (INDEC, 2010).

La República Argentina es clasificada en la actualidad como un país de ingreso mediano-alto, con un PIB anual de algo más de 446.044 millones de dólares, una población de algo más de 40 millones de personas y un ingreso medio per cápita de 10.943 dólares. No obstante, la distribución del ingreso es desigual. En 2012 los datos oficiales indicaban que el 10\% de la población con mejores remuneraciones concentró el $25,5 \%$ de los ingresos totales, mientras que el 10\% más pobre concentró el 1,6\% (INDEC, 2012).

El nivel de pobreza en el país evolucionó desde un 19,9\% de su población en 1992 a un 38,8\% en 2001. En 2002, luego de la devaluación de la moneda y la crisis política institucional, el porcentaje de población con ingresos por debajo de la línea de pobreza alcanzó un 51,7\% del total de su población nacional, mientras que un $25,2 \%$ se encontraba en su grado extremo o indigencia (FIDA, 2010).

El porcentaje de la población con niveles de pobreza e indigencia son, en la actualidad, un tema de debate en la Argentina, debido a las distintas fuentes para registrar los niveles de inflación contra los que se miden los índices de pobreza e indigencia. La información oficial proporcionada por INDEC (2010) a partir de la Encuesta Permanente de Hogares, sostiene que la pobreza en el país alcanza al 9,9\% de la población (alrededor de 4 millones de personas) los cuales 2,5\% (casi un millón de personas) se encuentran en la condición de indigencia. Por su parte, la Universidad Católica Argentina a través de su Encuesta de la Deuda Social Argentina, eleva ese número a prácticamente el doble: 8,5 millones de pobres y 2 millones de indigentes para la misma época. No obstante, en ambos casos, las fuentes oficiales y privadas coinciden en un proceso de mejora progresiva de los indicadores, más intenso en el período 2003-2007 y más lento a partir del 2007, debido al aumento de los programas asistenciales y del gasto social en general, la recuperación del empleo y los incrementos salariales que acompañaron a la inflación (UCA, 2011).

La población rural de la Argentina, entendida como aquella residente en centros poblados de menos de 2.000 habitantes y en áreas dispersas, equivale a algo menos del 10\% de la población, y se estima que cerca de un tercio del total (alrededor de un millón de personas) son pobres, prevaleciendo entre sus integrantes la población indígena, las mujeres, los jóvenes y los trabajadores no permanentes sin tierras (Banco Mundial, 2007). El nivel de pobreza en las regiones del norte del país continúa siendo elevado, llegando a casi el $26 \%$ en el noreste y al $21 \%$ en el noroeste, con niveles de indigencia del $7,1 \%$ y $5,3 \%$ respectivamente (FIDA, 2010). 
El sector agropecuario es muy importante en Argentina. Este país es uno de los principales productores mundiales de alimentos, con un sector agrícola/ganadero y agroindustrial moderno, con explotaciones empresariales muy capitalizadas y una agricultura familiar relevante en términos económicos y sociales. Agricultura y ganadería representan el $6 \%$ del PIB y con la agroindustria supera el $20 \%$. Entre 2005 y 2012 las exportaciones de bienes argentinos crecieron desde 40.013 hasta 83.950 millones de dólares, experimentando un alza del 103\%. Las exportaciones de origen agropecuario representan cerca del $60 \%$ del total de las exportaciones de bienes y servicios, el $18 \%$ del PIB y el $22 \%$ del valor agregado. La agricultura es una importante fuente de puestos de trabajo, generando alrededor del $20 \%$ del total si se incluyen el transporte y el comercio relacionados con el sector (Ministerio de Economía de la Nación Argentina, 2013).

La agricultura familiar, en paralelo a una agricultura y ganadería fuertemente capitalizada, mantiene un papel importante en la producción y en la estructura socio-económica del medio rural. En 2002, con datos del último censo nacional agrario disponible, se identificaban 251.116 explotaciones de "agricultura familiar" (el 75\% del total de explotaciones agrarias) que controlan 30,9 millones de hectáreas (equivalentes al $17,7 \%$ de la superficie total) y generan el $19 \%$ del valor total de la producción agraria nacional.

Este tipo de explotaciones familiares tienen como residentes a 823.235 personas y aportan el $64 \%$ del total del empleo agropecuario nacional. Su presencia es mayoritaria en el noroeste y nordeste del país (entre un $78 \%$ y un $92 \%$ del total), y disminuye en importancia en las regiones de Cuyo, Pampeana y Patagonia (representan entre el 60 y $69 \%$ de las explotaciones). En cuanto a los productos, las explotaciones familiares representa entre el 85 y el $94 \%$ de los establecimientos que producen tabaco, algodón, yerba mate, caña de azúcar, papa, cebolla, acelga y tomate y más del $50 \%$ entre los que producen granos (maíz, soja, trigo y girasol) (Obschatko, 2009).

En el caso de las cooperativas agrarias, debido a la intensa actividad de promoción del asociativismo como estrategia de desarrollo durante la última década, cabe señalar que al 31 de diciembre de 2010 el número total de cooperativas llegaban a 1.606, de las cuales 966 ( $60 \%$ del total) fueron creadas entre los años 2001 y 2010, aunque de ellas sólo se encontraban en situación regular 364 (38\%) (Obschatko et al., 2011:80). A pesar de ello, en conjunto las nuevas cooperativas duplican prácticamente el número de cooperativas activas regulares existente en la década de 1990 (Lattuada et al., 2011:20). Cerca del 60\% de las cooperativas agropecuarias del país se dedican al acopio y venta con especial peso en las provincias que integran la región pampeana y un $33 \%$ de las mismas desarrolla procesos de elaboración agroindustrial de sus manufacturas, con significativa concentración de casos en las regiones del Noreste (NEA) y Cuyo (Lattuada et al., 2011:32).

Asimismo, surgieron centenares de asociaciones económicas que, por diversos motivos, no adoptaron la forma jurídica de cooperativas y que han venido orientando su actividad según una lógica multifuncional, que les permitió trascender la esfera del mercado para desplegarse con similar intensidad tanto en el espacio público del Estado, como en el ámbito de la sociedad civil, buscando apoyo téc- 
nico y económico, así como reconocimiento político y social. Para el año 2010, se puede estimar un número de 3.200 grupos asociativos creados en el marco de tres de los programas de desarrollo rural del Instituto Nacional de Tecnología Agropecuaria (INTA, 2010) y alrededor de 8.700 en el marco de cinco de los programas del Ministerio de Agricultura Ganadería y Pesca de la Nación (MAGyP) (FIDA, 2013)..$^{5}$ Con el fin de brindarles asistencia técnica, capacitación y financiamiento, dichos programas presentan estrategias grupales y asociativas de intervención para lograr aumentar escala productiva, reducir costos, ganar capacidad de negociación, mejorar los ingresos familiares o la seguridad alimentaria de los beneficiarios.

2.1. Las transformaciones del contexto argentino en la década de 1990 y su impacto en el sector agropecuario y su red asociativa

El sector agropecuario argentino se expresa en la actualidad en una densa red asociativa construida a partir de diversas formas organizativas y tramas de articulación privado-públicas, en las que participan productores agropecuarios y población rural de diferentes condiciones y disponibilidad de recursos económicos y productivos.

Esta red asociativa se ha ido construyendo desde los inicios de la agricultura en la Argentina, como lo reflejan la aparición de las primeras organizaciones gremiales y económicas (cooperativas) hacia fines del siglo XIX, y en buena medida han sido producto tanto del dinamismo de las fuerzas productivas y sociales en el agro, como de las políticas públicas. Estas diversas formas asociativas de mayor formalización y presencia territorial han sido estudiadas extensamente por la literatura académica especialmente a partir de 1980 - (Lattuada, 2006).

No obstante, la retracción del Estado en la década de 1990 y los cambios estructurales en la economía, contribuyeron a una intensificación del pluralismo asociativo en el agro, con el surgimiento de cientos de nuevas asociaciones o proyectos asociativos, en algunos casos autogenerados por las condiciones del nuevo contexto económico, y otros promovidos activamente por los programas de desarrollo rural focalizados, tanto públicos como privados, que incorporaron la estrategia asociativa como base de su intervención en favor de los sectores de la agricultura familiar en los estratos medios y bajos de la estructura agraria.

En el escenario abierto en la década de 1990, dos ejes centrales trazaron transformaciones estructurales sobre el sector agropecuario argentino y sus asociaciones de productores. Por una parte, los cambios en la economía mundial reformularon la situación de ventajas comparativas tradicionales, exigieron una mayor articulación y dependencia del sector primario al capital industrial, comercial y financiero, y subordinaron algunos instrumentos de las políticas económicas domésticas a decisiones y

5.- Programas Minifundio, Cambio Rural y PROFAM del INTA y PRODERNOA, PROINDER, PROVIAR, PROSAP y PRODEAR del MAGyP. 
acuerdos supranacionales. Por otra, se aplicaron políticas internas basadas en planes de ajuste estructural que reformaron las dimensiones y funciones del Estado y del mercado a partir de la reducción de organismos y regulaciones estatales, la privatización de empresas públicas, la búsqueda de saneamiento fiscal, la apertura externa unilateral de la economía y un acelerado proceso de integración regional (Cf. Obschatko, 1994).

En este contexto de "ajuste", buena parte de los países de América Latina, iniciaron procesos vinculados con las reformas estatales sugeridas por los organismos financieros, particularmente por el Fondo Monetario Internacional (FMI). En Argentina, dos leyes dieron el puntapié inicial de lo que sería una década de retiro del Estado en la sociedad y el contexto para la aplicación de estrategias políticas cuyo saldo generalizado fueron el aumento de la desigualdad y la concentración económica: la Ley 23.696 de Emergencia Económica y Social y la Ley 25697 de Reforma del Estado (1989) (Cf. Neffa, 2010). La política macroeconómica argentina, basada en la denominada convertibilidad -que permitió la paridad peso/dólar-, organizó buena parte de las políticas públicas que acentuaron su carácter asistencial, técnico o sanitario dejando su clásico rol de sostén y protección de la producción agropecuaria a partir de los entes reguladores que desaparecen por estos años. ${ }^{6}$

Desde el punto de vista de las reformas institucionales en la esfera pública sectorial, el proceso tuvo efectos en desmantelar las normas y organismos del viejo orden, pero se manifestó incompleto y provisional en la construcción de un nuevo sistema. Muchas de las innovaciones institucionales estaban asentadas en programas de corto plazo basados en préstamos de organismos internacionales, bajo el supuesto de que las reformas significaban una reducción del aparato estatal en busca del equilibrio fiscal.

El resultado de las reformas estructurales llevadas a cabo durante la década de 1990, significó para el sector agropecuario un camino paradójico. Por una parte, duplicó la producción y la exportación de granos y otros productos de este origen, así como la venta de insumos, maquinaria y equipamiento, acelerando la modernización tecnológica del sector. Pero, por otra, generó una mayor concentración de la estructura agraria, a partir de un vertiginoso proceso de endeudamiento y expulsión de pequeños y medianos productores, cuyas explotaciones no lograron ser reconvertidas con los apoyos públicos implementados durante esa década. ${ }^{7}$

En este contexto, una serie de problemas comunes se manifestaron en las asociaciones reivindicativas agrarias tradicionales (Sociedad Rural Argentina, Federación Agraria Argentina, Confederaciones Rurales Argentinas, y Confederación Intercooperativa Agropecuaria): la reducción

6.- En el sector agropecuario, las medidas de retraimiento del Estado en sus funciones reguladoras implicaron la eliminación de una serie de entes de control tales como: la Junta Reguladora de Granos, la Junta Nacional de Carnes, la Dirección Nacional del Azúcar y la Comisión Reguladora de Yerba Mate.

7.- En el período intercensal 1988-2002 el número de EAPs. con límites definidos menores a 500 hectáreas disminuyó en 82.854 unidades y 5.715.547 hectáreas, y en el otro extremo las de más de 10.000 hectáreas tuvieron una reducción de 75 unidades, con 623.442 hectáreas. Por el contrario, la franja de EAPs que va de las 500 a 10.000 hectáreas aumentó su número en 1.922 unidades, y la cantidad de tierra en explotación en 3.719.011 hectáreas (INDEC, 1988 y 2002). 
del número de asociados, una menor participación de los productores en las actividades de su organización, un creciente cuestionamiento de la representatividad de sus dirigentes, la necesidad de redefinir nuevos roles institucionales, la reducción o desaparición de las fuentes históricas de recursos económicos -afectando su capacidad de acción-, la disminución de su influencia en el proceso de toma de decisiones de las políticas públicas y el surgimiento de numerosas nuevas asociaciones que buscaban competir por la representación de los productores rurales y el lugar de interlocutores válidos ante el Estado y otros grupos de interés en temas específicos (Lattuada, 2006).

Por su parte, las cooperativas agropecuarias, ejemplo hasta ese momento de las más importantes asociaciones económicas (no reivindicativas) del sector, integradas mayoritariamente por medianos y pequeños productores, ingresaron en un proceso de deterioro progresivo. El número de cooperativas, de asociados y el nivel de su actividad económica disminuyó significativamente ${ }^{8}$ como consecuencia del proceso de crisis y concentración que afectó sus bases sociales, de la debilidad financiera de muchas de sus entidades, de las mayores exigencias de competitividad en el comercio y transformación de granos y de las deficiencias gerenciales que se hicieron evidentes ante el nuevo contexto económico, cuando los efectos inflacionarios y de las devaluaciones de la moneda ya no compensaban las deficiencias de gestión.

La quiebra y desaparición de muchas de ellas constituyeron marcas negativas en la conciencia colectiva de numerosos productores respecto de las empresas asociativas tradicionales. En las cooperativas de mayor envergadura y solidez -Agricultores Federados Argentinos, Asociación de Cooperativas Agrarias, SanCor Cooperativas Unidas Limitada- comenzaron a plantearse tensiones entre los principios doctrinarios y las prácticas cotidianas. La lógica empresarial tiende a imponerse sobre la mutualista como condición de viabilidad en un contexto caracterizado por la apertura, desregulación y globalización de la economía, y el alto grado de vulnerabilidad de sus asociados que ponía en riesgo la solvencia de estas organizaciones (Lattuada et al., 2011).

En el nuevo contexto la supervivencia y viabilidad de las explotaciones pasaba por la eficiencia micro-económica de los productores en el mercado, y por las condiciones y apoyos que pudieran generar sus propias formas de organización y asociación para su reconversión y competitividad, soluciones que ya no encontraban en las asociaciones gremiales o económicas tradicionales.

De este modo, los productores se vieron impulsados a la búsqueda de formas de organización y asociación que dieran respuestas adecuadas a necesidades concretas e inmediatas, predominantemente aquéllas de carácter productivo, tecnológico o comercial, que otorgaran viabilidad a sus explotaciones. Tanto en lo referente a las asociaciones reivindicativas como económicas, esta búsqueda

8.- Las cooperativas agropecuarias disminuyeron en número alrededor de un $21 \%$ durante el período 1985-1994, con una reducción de su participación en el volumen de almacenaje de granos de la Argentina del $26,9 \%$ al 20,4\%, de su actividad en la faena de ganado del 2,05\% a sólo el 1,28\%. También disminuyó el aporte cooperativo a las exportaciones agropecuarias del país del 17,1\% al 5,7\% entre los años 1980 y 1996 (Lattuada, 2006:146-152). 
exigía una red de actores más amplia y heterogénea, generando una explosión pluralista de asociaciones de todo tipo en el territorio nacional.

Este proceso tuvo dos factores que confluyeron en su gestación y dinámica. En primer lugar las iniciativas asociativas de los propios actores socioeconómicos en respuesta al cambio de las reglas de juego. En segundo lugar, los programas de desarrollo rural focalizados que, en el marco de una política compensatoria, promovieron el asociacionismo entre los sectores más vulnerables de la estructura agraria en la búsqueda de alguna alternativa de mejorar las condiciones de escala, intensificar y/o diversificar la producción, participar en nuevos eslabones de la cadena productiva y, en la medida de lo posible, articularse con mercados dinámicos.

La implementación de programas públicos de asistencia y desarrollo de pequeños y medianos productores rurales tuvo una importancia creciente en el fomento de formas asociativas de diverso tipo en el medio rural. Con escasos antecedentes previos en la historia Argentina, durante la década de 1990 se instalaron y multiplicaron numerosos programas de este tipo, dependientes de diferentes agencias estatales -Instituto Nacional de Tecnología Agropecuaria (INTA), Secretaría de Agricultura Ganadería, Pesca y Alimentos (SAGPyA)- y fuentes de financiamiento -Presupuesto Nacional, Banco Interamericano de Desarrollo (BID), Banco Mundial (BM), Fondo Internacional de Desarrollo Agrícola (FIDA) - (PROINDER, 2003).

Estos programas eran diversos en sus objetivos. Algunos ponían énfasis en la competitividad, la vinculación de los productores al mercado y la capitalización de las explotaciones, mientras que otros priorizaban el mejoramiento de las condiciones mínimas de vida de los beneficiarios. No obstante, en su amplia mayoría brindaban asistencia técnica, capacitación, apoyo socio-organizativo y, en algunos casos, también financiamiento a través de estrategias grupales y asociativas con el objeto de aumentar escala, reducir costos, ganar capacidad de negociación, mejorar los ingresos familiares 0 la seguridad alimentaria de los beneficiarios.

Los resultados de estas acciones se manifestaron en numerosas experiencias asociativas en los territorios donde los programas tuvieron intervención. Un estudio del BID y PNUD (2000:45) indica que el 63\% de las organizaciones de base que existían en el año 2000 en la provincia de Jujuy, por ejemplo, fueron creadas entre 1990 y 2000. Una tendencia confirmada por Cowan Ros (2010:232), quien de una muestra de 35 organizaciones sociales analizadas en la Quebrada y la Puna para el año 2002, constató que el 93\% tuvo su origen entre 1994 y 2002. Esta realidad se comprueba también en otras regiones del país abarcando diversos grados de formalización y desarrollo organizacional, formas jurídicas, tipos de actividad productiva, comercial o reivindicativa, así como características socio-productivas de sus integrantes (Schiavoni, 2001, Neiman et al., 2006, CEDES, 2007, CIET, 2007, Bocco et al., 2008). 
Siendo pionero en cuanto a las estrategias de desarrollo focalizadas en los pequeños productores agropecuarios, el Programa de Crédito y Apoyo Técnico para Pequeños Productores del Noreste Argentino (PNEA, 1991-1996), al año y medio de su inicio (junio de 1993) había brindado servicios de asistencia técnica y financiera a 3.300 productores organizados en 470 grupos distribuidos en las provincias de Corrientes, Formosa y Misiones (Baudrón, 1993:78). ${ }^{9}$ Para el año 2000 el programa Minifundio del INTA (1985 y continua) había brindado asistencia a 23.000 productores y dos años después, mantenía servicios activos para 11.614 productores en 43 proyectos, 324 grupos, 49 cooperativas, y 8 asociaciones (PROINDER, 2003). ${ }^{10} \mathrm{~A}$ fines del año 2002, de acuerdo a las mismas fuentes oficiales (PROINDER, 2003), se reconocían como beneficiarios del Programa Federal para la Reconversión Productiva de la Pequeña y Mediana Empresa Agropecuaria (Cambio Rural) a 30.000 productores acumulados en una década (1993-2002) y 8.102 productores como beneficiarios activos al momento del registro. En el marco de dicho programa se conformaron 610 grupos sin subsidio (5.490 productores); 102 grupos con subsidio (1.122 productores); 7 grupos grandes (220 productores); 49 cooperativas (más de 4.000 productores); 4 uniones y Federaciones de Cooperativas y 31 proyectos de Apoyo al desarrollo local (más de 1000 productores). ${ }^{11}$

En este contexto, puede afirmarse que la constitución de nuevas formas asociativas durante la década de los 90 tienen origen a partir de distintas fuentes: auto-generadas por los propios individuos interesados; impulsadas desde organizaciones preexistentes; o promovidas por programas estatales. Sus fines u objetivos también han sido diversos (gremiales, productivos, tecnológicos, comerciales), y pueden encuadrarse en los dos tipos ideales que caracterizan al asociativismo agrario: reivindicativas y no reivindicativas (Moyano Estrada, 2002). No obstante, en las motivaciones de los productores participantes se encuentra un denominador común: la búsqueda de soluciones colectivas acotadas -local, por producto, etc.- a los problemas planteados por las nuevas condiciones económicas e institucionales, y cuya solución no las encuentran en las históricas asociaciones reivindicativas del agro.

9.- La estrategia del PNEA contemplaba la constitución de Consorcios Productivos, integrados por un número de 4 a 12 productores. Estos podían conformar, en un segundo nivel de agregación, Sociedades de Hecho, que a su vez integraban Comités por Producto para compartir información de mercadeo.

10.- El Programa Minifundio tiene como objetivo reforzar el autoconsumo de las familias minifundistas, promover la incorporación de tecnologías apropiadas y la conformación de organizaciones locales, con el fin de poner en marcha emprendimientos productivos comunitarios. Mediante su gestión y con la participación de otros actores locales, se busca mejorar la competitividad productiva, promover la diversificación y la integración a procesos agroindustriales, como medios para acceder a diferentes mercados con mayor probabilidad de éxito (Lattuada et al., 2012).

11.- El objetivo planteado por Cambio Rural consiste en promover una mejora en la competitividad de las empresas de los pequeños y medianos productores, que permita aumentar el ingreso neto en el corto plazo, y crear las bases para una evolución favorable en el largo plazo. Con este fin, brinda asistencia técnica directa a los productores, a través de una metodología grupal, promoviendo mejoras en la organización productiva y capacidad empresarial, así como una más fluida vinculación con fuentes de financiamiento, los procesos agroindustriales y los agronegocios (Lattuada, 2000). 


\subsection{Jerarquización de la agricultura familiar en los programas de desarrollo rural $y$ fomento de formas asociativas del sector a comienzos del nuevo milenio}

Las condiciones que definieron aquel contexto de los años de 1990, volvieron a cambiar en forma dramática a partir de la crisis del año 2001. Las reglas de juego existentes durante una década desaparecieron junto a la crisis del sistema financiero, la salida de la convertibilidad (paridad peso argentino/dólar americano), la declaración del default en el pago de la deuda externa, un cuestionamiento masivo del sistema de representación política y del sistema judicial y una creciente incertidumbre política, económica y social en el conjunto de la ciudadanía.

La situación comienza a modificarse a partir de 2003, cuando, en palabras de lazzetta (2005), comienza una lenta y gradual reconstrucción del Estado. "Se incrementan las reservas, mejoran las cuentas fiscales y, en conjunto, hay una cierta recuperación de las capacidades estatales" (lazzetta, 2005:45). Los cambios en materia de políticas macroeconómicas se apoyaron hasta 2009 en: a) el mantenimiento de un tipo de cambio competitivo; b) prudencia fiscal y c) políticas de incremento de ingreso; d) superávit gemelo (fiscal y comercial); e) estímulo al consumo y subsidios a la población muy pobre; f) el aumento del empleo formal y recomposición salarial. Estas políticas permitieron reducir la pobreza a casi un tercio (del 58\% en 2002 al 20\% en 2010) y el desempleo cayó del $21,5 \%$ al $8 \%$ en el mismo periodo. ${ }^{12}$

De este modo, a partir del año 2003, un nuevo paradigma en la relación Estado-mercado se instala en la Argentina y la región. El primero ha vuelto a ocupar un rol decisivo en la redistribución de costos y beneficios de la sociedad en general y del sector agropecuario en particular, en un marco donde la política se consolida primero tibiamente y luego en forma explícita y creciente como reguladora de la economía y del mercado. Desde la nueva concepción de la relación política/economía y Estado/mercado, el mayor excedente generado ya no es apropiado exclusivamente por los actores privados a través de la redistribución del mercado. Ahora es el Estado quien recauda una parte significativa de aquél para redistribuirlo entre diferentes actores sectoriales y extra sectoriales.

La creación del Ministerio de Agricultura Ganadería y Pesca de la Nación (MAGyP) en el año 2009 y la elevación de la Subsecretaría de Desarrollo Rural y Agricultura Familiar -creada un año antes- al rango de Secretaría de Estado, contribuyó decididamente a consolidar en la agenda pública la problemática de la agricultura familiar y su representación.

La agricultura familiar no había sido históricamente una cuestión relevante de la agenda sectorial, aunque la experiencia desarrollada durante la década de 1990 sirvió para la creación de un tejido conectivo entre productores, técnicos, organizaciones y agencias estatales que fortalecieron progresivamente su visibilidad. En la primera década del siglo XXI, su problemática fue creciendo en impor-

12.- No obstante, a partir de la crisis económica internacional de 2009 en adelante la mayoría de estos indicadores han sufrido un estancamiento o se han ralentizados (Véase al respecto, entre otros, CENDA, 2010). 
tancia en la región del Mercado Común del Sur -MERCOSUR- y en el ámbito nacional a partir de una estrategia gubernamental explícita en la reorientación de los programas de desarrollo rural con el objeto de fortalecer la organización y representación de intereses de estos sectores rurales postergados. ${ }^{13}$

Nuevos programas y estrategias de desarrollo rural se sumaron o reemplazaron a las existentes, muchas de ellas con una estrategia específica del fortalecimiento de las organizaciones de los productores.

A diferencia de la década anterior, con un nuevo contexto político y económico argentino se han reorientado los fines perseguidos para el fortalecimiento de las asociaciones de la agricultura familiar. En esta nueva etapa se busca en los procesos asociativos no sólo alternativas económico-productivas para enfrentar sus debilidades en el mercado, sino fortalecer cierto grado de empoderamiento de aquellos sectores hasta ahora invisibles en la interlocución con el Estado, dotándolos a partir del fortalecimiento de su organización de un reconocimiento y mayor capacidad de participación en los procesos de toma de decisión de las políticas públicas.

Los pequeños productores y la agricultura familiar adquieren en esta etapa un lugar destacado en la agenda pública respaldada por la experiencia de dos décadas de trabajo en el terreno de una extensa y compleja red de actores sociales integrada por productores, organizaciones, técnicos, ONGs, agencias estatales en sus diversas competencias territoriales.

Muchas de las asociaciones creadas a partir de la promoción de las agencias estatales han confluido en el denominado Foro Nacional de la Agricultura Familiar (FoNAF) que, en pocos años supo convertirse en un interlocutor del Estado en algunos aspectos del desarrollo rural (Márquez, 2007). En el Foro participan alrededor de 900 asociaciones de pequeños productores de distinto tipo -reivindicativas, no reivindicativas, económicas- 14 aunque no se ha podido acceder a fuente o registro oficial alguno que lo documente, y si bien desde sus inicios estuvo estrechamente asociado a las acciones llevadas adelante por el Estado nacional, en los primeros días de diciembre del 2011 sus asociaciones conformaron jurídicamente la Federación de Organizaciones Nacionales de la Agricultura Familiar cuyo objeto es constituir una representación sectorial independiente del Estado y de las asociaciones reivindicativas históricas (Véase www.lahoradesalta.com.ar/2012/02/09).

Además de las organizaciones participantes del Foro surgieron otras iniciativas de agrupaciones muy diversas con integrantes heterogéneos que incluyen desde miembros en forma individual como profesionales y técnicos hasta representantes de ONGs. y universidades, así como asociaciones o

13.- En la década de 1990 dicho concepto era casi ajeno al vocabulario del desarrollo rural, frente a categorías como las de "pequeño productor" o "minifundista", siempre relacionados con situaciones de pobreza rural, mientras que a partir de 2003 el concepto de agricultura familiar comienza a aparecer como una noción más abarcadora que incluye un abanico de actores tales como los denominados "productores familiares capitalizados" y aún a población con actividades no agrarias (Nogueira y Urcola, 2013).

14.- Participan organizaciones de carácter histórico, como el Movimiento Agrario Misionero (MAM) o el Movimiento Campesino de Santiago del Estero (MOCASE) y la Federación Agraria Argentina (FAA). Esta última, tradicional organización corporativa del agro argentino, sólo inicialmente participó del mismo. 
grupos de desocupados, productores sin tierras, campesinos y miembros de comunidades aborígenes que plantean una posición de mayor autonomía del Estado o de asociaciones reivindicativas tradicionales. ${ }^{15}$

En el nuevo contexto, las iniciativas asociativas continúan considerándose como una alternativa económica valiosa para los pequeños productores, pero en esta nueva etapa el empoderamiento de sectores socioeconómicos tradicionalmente invisibles y postergados a partir del fortalecimiento de su organización social y política ocupan un lugar tanto o más importante que los fines económicos, aunque con un alto nivel de riesgo de transitar desde un clientelismo técnico a un clientelismo político. 16

Este proceso tan relevante como silencioso, se encuentra operando en el ámbito rural y plantea numerosos interrogantes sobre su dimensión, características y potencialidad. ¿En qué medida muchas de estas organizaciones se constituyen a partir de la iniciativa de bases legítimas en los productores y población rural o fuertemente sostenidas por cuadros técnicos, profesionales y políticos? ¿Cómo evolucionan éstas organizaciones en su inserción territorial a nivel local y en su proyección regional o nacional? ¿Cuáles son los mecanismos de adaptación favorecidos por el accionar colectivo en relación con el mercado, el Estado y la sociedad en diferentes contextos económicos y políticos? ¿En qué medida pueden consolidarse como actores dinámicos del desarrollo en los territorios? Lejos de constituir una estructura cristalizada o de brindar respuestas acabadas, éste es un proceso dinámico que crea, destruye y recrea relaciones sociales, económicas y políticas abriendo un amplio campo para el despliegue de estrategias de investigación sobre la evolución y características de estos procesos asociativos en pleno desarrollo que requieren de un encuadre conceptual y operativo para su análisis e interpretación.

15. - Un ejemplo lo constituye el denominado Movimiento Nacional Campesino Indígena (MNCl) integrado por individuos y asociaciones reivindicativas y no reivindicativas de muy diverso grado de formalización como Red Puna, Encuentro Calchaquí, la fracción Vía Campesina del Movimiento Campesino de Santiago del Estero (MOCASE), Movimiento Campesino de Córdoba (Apenoc, Ucan, Ocunc, Ucatras, Organizaciones de Cruz del Eje), Unión de Trabajadores Rurales Sin Tierra de Mendoza, Unión de Jóvenes Campesinos de Cuyo, Movimiento Campesino de Misiones.

16.- Sobre los riesgos y variantes del clientelismo en las asociaciones rurales puede verse para el caso de Chile: Durston (2001a) y para Argentina: Lattuada et al. (2012). 


\section{3.- Aproximaciones conceptuales para la caracterización del asociativismo rural}

Desde un punto de vista analítico, la gran diversidad de asociaciones mediante las cuales los agricultores y ganaderos articulan sus intereses podría ubicarse en una especie de continuum en función de su menor o mayor grado de formalización. Estas formas asociativas pueden diferenciarse a partir de los fines de su constitución -desde una perspectiva teórica en cierto modo esquemática (Moyano Estrada, 2002, Moyano Estrada y Entrena Durán, 2002)- en al menos dos grandes grupos y un subgrupo específico que será de interés central para este trabajo:

a) Asociaciones Reivindicativas, entendiendo por ellas aquellas con mayor o menor grado de formalización institucional que defienden y promocionan los intereses generales de sus asociados, pero con beneficios al conjunto del colectivo que reúne similares condiciones, y tienen una fuerte impronta ideológica que condiciona sus discursos y estrategias de acción colectiva. Son un ejemplo de ellas las organizaciones gremiales patronales u obreras.

b) Asociaciones No Reivindicativas: son las que abarcan una multiplicidad de fines sociales o de servicios, habitualmente circunscriptos a temas o cuestiones específicas y que benefician con exclusividad a sus asociados directos, como los consorcios de riego, los grupos de intercambio de información tecnológica.

c) Asociaciones No Reivindicativas Económicas: similares en sus características y alcances a las no reivindicativas, pero con un fin económico específico que beneficia sólo al reducido núcleo de sus asociados. Esta formas cubren un amplio abanico de situaciones de menor o mayor formalidad y complejidad jurídica y organizacional que van desde los acuerdos informales y contratos entre personas, pasando por una heterogeneidad de formas intermedias: grupos informales y asociaciones civiles que desarrollan actividades de orden económico, sociedades comerciales de diferente tipo, y redes públicoprivadas con el objeto de concurrir asociativamente para la realización de alguna parte o todo el proceso productivo, comercial o de transformación.

Las asociaciones en el mundo rural son frecuentes, diversas y heterogéneas, de acuerdo a los fines perseguidos y las características de sus integrantes. No obstante, esa heterogeneidad se reduce cuando se focaliza al interior de las asociaciones, en particular en las asociaciones económicas, las que tienden a ser integradas por miembros de similares condiciones étnicas, culturales, económicas y socio-productivas.

Las formas de organización de mayor o menor formalidad jurídica adoptada suelen ser respuestas originales a situaciones concretas y por lo tanto no necesariamente encuadrarse dentro de formas institucionales más tradicionales o conocidas, como las cooperativas o las sociedades comerciales. 
En sentido amplio, se entiende por asociación, el agrupamiento de individuos creado para lograr un fin común. La asociación es un género que comprende muchas especies, las que varían de acuerdo a la legislación existente en cada país. Por ejemplo, en la Argentina son dos las formas jurídicas en las que pueden encuadrarse los agrupamientos de individuos con un fin común: asociativas y societarias (Formento, 1994), existiendo para cada una de ellas diferentes normas y organismos de control y regulación. Las primeras incluyen las asociaciones en sentido estricto, agrupaciones sin fines de lucro como las asociaciones civiles, mutuales, fundaciones y cooperativas, y las segundas, agrupaciones con un objetivo económico o de lucro, abarcan desde las Sociedades de Hecho hasta las Sociedades Anónimas y formas contractuales de asociación o de colaboración entre empresas como las Agrupaciones de Colaboración Empresaria y las Uniones Transitorias de Empresas, así como los instrumentos legales que caracterizan a la agricultura de contrato en sus diversas modalidades (Tort y Lombardo, 1994, Elgue y Chiaradía, 2007).

En la literatura académica existen posiciones encontradas respecto de considerar a las empresas y sociedades comerciales con fines de lucro como parte del asociacionismo, especialmente de aquel que se lo identifica como tercer sector, sociedad civil o economía solidaria (PNUD, 2000, Gaiger, 2004). Sin desconocer las diferencias existentes entre ambos agrupamientos esa perspectiva impide observar procesos dinámicos en la evolución de las propias organizaciones y de sus redes de vinculación con otros agentes del mercado. Aquello que en un inicio puede facilitar la organización por su simplicidad jurídica, administrativa o impositiva puede transformarse después en un obstáculo para su consolidación. En una asociación se puede obtener beneficios con la actividad realizada y aumentar el patrimonio de la institución, pero el asociado no lucra con esa ganancia y al retirarse encuentra limitaciones para recuperar su parte del patrimonio social o de las ganancias acumuladas a diferencia de un integrante de una sociedad comercial.

Las formas asociativas de interés común sin fines de lucro -fundamentalmente las Asociaciones Civiles y las Fundaciones- resultan más propicias para tareas de promoción, asistencia, capacitación y tutorías, mientras que las Cooperativas o las Sociedades Comerciales son más adecuadas para asumir la producción y la comercialización en los mercados formales. Las asociaciones no pueden operar comercialmente en el mercado y lo deben hacer a través de sus integrantes en forma individual, una opción imposible de sostener cuando el volumen del negocio crece, procurando extenderse fuera del radio local o intenta institucionalizarse.

Las asociaciones con mayor grado de formalización jurídica sean éstas asociaciones, sociedades comerciales y colaboraciones de empresas, se conforman con mayor frecuencia entre sectores sociales rurales con mayor disponibilidad relativa de recursos. En el caso de los pequeños productores y la población rural vulnerable en cambio, los grupos informales y consorcios de productores constituyen un mecanismo de bajo grado de formalización a través del cual se organizan. Estos suelen ser sociedades de hecho con la ventaja de la rapidez y simplicidad para su conformación inicial pero con limitaciones para su crecimiento organizacional. 


\section{LAS FORMAS ASOCIATIVAS DE LA AGRICULTURA FAMILIAR EN EL DESARROLLO RURAL ARGENTINO DE LAS ÚLTIMAS DÉCADAS (1990-2014)}

La elección de una determinada forma jurídica depende de muchos factores y básicamente de las características de los productores y sus objetivos: número de personas, capacidad económica, necesidad de contratar personal, tipo de mercados de destino, grado de transmisibilidad de las participaciones y apertura a la incorporación de nuevos participantes, entre otras (Tort y Lombardo, 1994). A ello se agregan las diferentes afectaciones impositivas que cada una de ellas contempla sobre la organización adoptada y sobre sus integrantes (Formento, 1994), así como los diferentes grados de exigencia y costos en la gestión de su administración.

Si bien en todos los países existen diversas opciones o alternativas de organización económica, los marcos jurídicos suelen ser rígidos y siempre ir detrás de las transformaciones que exige e implementa la sociedad en su adaptación a las cambiantes oportunidades y amenazas que plantea la vida cotidiana a sus miembros. El hecho de que muchas formas asociativas adoptadas por los integrantes de la agricultura familiar no se adecuen a sus necesidades es un indicador de la no correspondencia entre el marco institucional y la realidad rural que, como veremos más adelante, influye sobre la creación y consolidación de determinados actores en el sistema.

\subsection{Caracterización de las asociaciones económicas de la agricultura familiar}

El tipo de asociaciones económicas que definimos como de la agricultura familiar corresponde a aquellas cuyos asociados reúnen las características que definen esta categoría. Una categoría cuya delimitación no constituye un punto pacífico del debate académico abarcando criterios socioeconómicos, culturales y políticos. Por lo tanto, establecer una noción aceptable y operativa de la misma requiere partir de ciertos consensos básicos con la salvedad realizada de que el modelo obtenido no cuente con una aceptación generalizada.

Un primer integrante de la agricultura familiar, aunque como veremos más adelante no el único, lo constituyen los pequeños productores rurales, entendidos como aquellos que trabajan directamente en sus predios con la colaboración de miembros de su familia o grupo doméstico y cuyos recursos productivos -tierra, capital, ingresos- se encuentran relativamente limitados. Dentro de la categoría de agricultura familiar se acepta que estos pequeños productores puedan tener diferentes niveles de capitalización y aún contratar hasta un número máximo de asalariados permanentes. ${ }^{17}$ En otras palabras, la categoría abarca los pequeños productores más capitalizados, los que viven de su establecimiento pero no generan excedentes para crecer, y los de menores recursos productivos que no pueden vivir exclusivamente de lo generado en el establecimiento.

17.- En la propuesta de Obschatko (2009) para Argentina, el nivel de capitalización fue definido para cada región tomando en cuenta las actividades productivas predominantes y los siguientes indicadores: existencia ganadera, posesión y edad del tractor, superficie regada en cultivo a campo, tenencia de invernáculos, superficie con frutales y contratación de un máximo de 2 asalariados permanentes. 
Si bien su número y características pueden variar por región (ver apartado 1. Contexto argentino), constituyen un porcentaje mayoritario de los productores y trabajadores que residen en el medio rural y del total de los establecimientos agropecuarios registrados. Controlan un porcentaje menor de la tierra, sus cultivos son predominantemente intensivos y agroindustriales, pero su aporte productivo suele ser significativo en términos relativos. El nivel de instrucción formal alcanzado mayoritariamente es bajo y los registros de producción y contables son utilizados en una baja proporción. También en este segmento de productores resulta relevante la multiocupación o pluriactividad de sus integrantes que requieren de actividades laborales fuera de los establecimientos para aumentar sus ingresos (Obschatko, 2009).

La agricultura familiar no sólo puede caracterizarse por elementos morfológicos como los enunciados más arriba, sino también por ciertos aspectos culturales que definen una "forma de ser" y un "estilo de vida" que identifica a sus integrantes con la vida rural, aunque cada vez más en retraimiento y transformación (Balsa, 2006).

Finalmente, la agricultura familiar funciona como un concepto político que orienta los programas de intervención y desarrollo y que ha obtenido un amplio consenso en varios países del Cono Sur tal como se ha expresado en el marco de la Reunión Especializada sobre Agricultura Familiar (REAF) del MERCOSUR desde el año 2004. Desde esta perspectiva, la acción pública destinada a este sector excede lo estrictamente agropecuario para involucrar todas las actividades económicas generadoras de ingreso que las personas asentadas en el medio rural llevan adelante, incluidos el turismo, las artesanías, la agroindustria y otros servicios (Lattuada et al., 2012).

En síntesis, se puede afirmar que las asociaciones económicas de la agricultura familiar (AEAF) se encuentran integradas mayoritariamente por población rural vulnerable y de escasos recursos económicos, comunidades aborígenes, trabajadores que sin disponer de tierras tienen emprendimientos económicos en el medio rural (como las artesanías, el turismo, la pesca o la apicultura entre otros); los emprendimientos agroindustriales pequeños y medianos (elaboración de quesos, dulces, vinos, aceites, encurtidos, etc.); y los pequeños productores que dirigen o trabajan directamente en pequeñas y medianas unidades domésticas de producción que generan una parte importante de su ingreso. Las personas que componen este universo desempeñan un papel protagónico en la construcción social de los territorios rurales y de su identidad. Aquello que esta perspectiva destaca es la evidencia de la diferencia, la "otra agricultura", caracterizada por sujetos sociales con grandes asimetrías respecto de la agricultura empresarial en cuanto al acceso y disponibilidad de información, recursos productivos y poder de negociación, quienes expresan una manera diferente en el modo de sentir y construir su relación con el medio rural.

Estas características de integración de las asociaciones económicas de la agricultura familiar la asemejan a las empresas de la economía popular o solidaria. En ellas se abordan diversos tipos de actividad económica basadas en la asociación voluntaria donde predominan relaciones de reciproci- 
dad y de cooperación y un cierto hibridismo entre arreglos formales e informales, prácticas no mercantiles e integradas al mercado a favor de intereses comunes (Nyssens, 1996). Una característica distintiva de estos emprendimientos es el carácter multifuncional que asume su actividad, condición que los lleva a actuar simultáneamente en la esfera económica, social y política para obrar concretamente en el campo económico al mismo tiempo que interpelan los restantes planos de participación. Su objetivo principal es suplir las necesidades materiales de sus miembros así como sus aspiraciones no monetarias de reconocimiento, inserción social y autonomía, y para ello requieren que su actividad trascienda la frontera mercado/Estado. Actúan en lo que la literatura sobre capital social identifica como una interface, el área de intercambio de bienes, servicios e información entre varios sistemas de relaciones sociales de diferente carácter -mercado, sociedad y Estado- (Durston 2001b).

Por ello, la tendencia a organizarse en asociación económica que no están formalmente constituidas como cooperativas en la mayoría de los sectores de la agricultura familiar, es motivada -aunque no en forma excluyente- por las necesidades de resolver problemas emergentes y básicos o la oportunidad de encontrar alternativas de mejora en las condiciones de vida, ya sea en forma de iniciativa propia y autónoma o con mayor frecuencia por la convocatoria o gestión de una institución pública o de la sociedad civil que facilite las condiciones para su realización. Si bien este tipo de asociación es condicionada por el accionar estatal, desde su reconocimiento legal y jurídico, existen ciertos precursores culturales y sociales que pueden facilitar esa integración -memoria social, identidad y etnicidad, religión, vecindad, amistad, parentesco, y relaciones de reciprocidad, prestigio, o reconocimiento- (Durston, 2001b).

\subsection{Asociaciones económicas de la agricultura familiar y agregado de valor}

Las AEAF pueden tener como objetivo una o múltiples actividades o procesos: a) adquirir insumos y/o equipamiento en forma conjunta para su utilización en proyectos productivos comunes 0 individuales de cada uno de sus asociados; b) realizar en forma colectiva la producción primaria en tierras propias, de asociados o de terceros; c) acopiar, limpiar, seleccionar, clasificar, empacar, almacenar, conservar y transportar la producción en común o de sus asociados; d) transformar la producción primaria propia, de asociados y de terceros; e) comercializar la producción común y/o de sus asociados y f) generar factores de diferenciación en base a atributos especiales o de calidad (denominaciones de origen, calidad controlada, producción orgánica, certificación de comercio justo, etc.).

Estas asociaciones no realizan necesariamente todas estas actividades sino algunas de ellas con distinto grado de desarrollo y posibilidades de combinación, siendo las de menor frecuencia aquellas que requieren mayores recursos económicos y organizativos como la comercialización y especialmente la transformación de la producción. Si bien en todos los casos se supone que cada una de estas actividades al ser realizada en forma asociativa posibilita la obtención de menores costos y una mayor capacidad de negociación al ganar escala, suele entenderse equivocadamente que el agregado de 
valor reside sólo en la etapa de industrialización o transformación del producto primario, siendo ésta sólo una de las distintas actividades de post cosecha -identificadas como c), d) y e)-. ${ }^{18}$

En cualquier caso, en la medida que las asociaciones van asumiendo algunas de estas actividades de agregado de valor requieren una mayor complejidad organizacional y jurídica debido a los mayores requisitos estatales (sanitarios y legales) y de mercado (contractuales).

En cierto modo esquemático, podríamos agrupar tres niveles de complejidad en el agregado de valor en el que pueden participar estas asociaciones, los cuales a su vez presentan internamente diferencias cualitativas importantes:

a) Acopio y acondicionamiento que puede incluir actividades como extracción, limpieza, lavado, selección, embalaje y transporte (desde finca y/o a destino) de la producción primaria; tareas por la cual se cobra el servicio a los asociados y terceros. ${ }^{19}$

b) Comercialización de la producción por cuenta de sus asociados y terceros, o por cuenta de la propia asociación en la medida que dispone de algún tipo de acuerdo de provisión por parte de sus asociados. En el primer caso la asociación cobra una comisión por el servicio que presta a terceros, mientras que en el segundo es la asociación quien compra, vende y asume la responsabilidad ante la demanda. Esta puede desarrollarse en mercados locales, regionales, nacionales 0 aún internacionales. ${ }^{20}$

c) Transformación de la producción primaria a partir de procesos de diferente grado de complejidad que alteran la conformación física o química inicial del producto. ${ }^{21}$

18.- Esta noción amplia de agregado de valor es promovida desde los enfoques de la Agroindustria Rural (AIR) del Programa Cooperativo de Desarrollo de la Agroindustria Rural en América Latina y el Caribe (PRODAR), y por el Programa de Agronegocios y Comercialización (PAC) del Instituto Interamericano de Cooperación Agrícola (IICA) y los Sistemas Agroalimentarios Localizados (Boucher y Riveros, 1995).

19.- Aqui pueden observarse situaciones como el simple acopio y almacenamiento hasta aquellas que requieren equipamiento especializado (salas de extracción de miel, cámaras de frío positivo) y mayor conocimiento aplicado en la diferenciación del producto (selección, tipificación, normas de calidad y de buenas prácticas, etc.).

20.- El comercio en mercados locales implica menores exigencias que el acceso a mercados nacionales o internacionales y la comercialización individual que la requerida para la participación en redes privadas -integración vertical, consorcios de exportación, clusters- o público/privadas -ferias francas, acuerdos de provisión-

21.- El grado de complejidad del proceso puede variar desde un simple congelado en bloque de frutas hasta procesos altamente sofisticados como puede ser la elaboración de vinos y aceites entre otros productos. 


\section{4.- Tipología de Asociaciones Económicas de la Agricultura Familiar}

Toda tipología es una construcción teórica útil para ordenar una realidad compleja que en la práctica manifiesta una gran diversidad, heterogeneidad y mezcla de caracteres. La tipología simplifica la realidad que pretende ordenar, y en esa simplificación radica su fertilidad analítica y capacidad explicativa. El problema es que no se debe tratar como una categoría real lo que es una abstracción, es decir, un tipo ideal, sino que, a la hora de utilizarlo, se debe realizar un ejercicio de operacionalización para que puedan caber en él las distintas formas en que se manifiesta la realidad.

Una diversidad de Asociaciones Económicas de la Agricultura Familiar (AEAF) pueden ser identificadas en el territorio argentino. Con el objeto de sistematizar y caracterizar la diversidad de AEAF en el sector rural procederemos en esta sección a construir una tipología de asociaciones y sus redes de colaboración para llegar al mercado con diversos grados de formalización y complejidad organizacional a partir de una serie de casos que fueran presentados en un trabajo anterior (IICA, 2011). Éstos no necesariamente agotan la totalidad de las experiencias existentes en la realidad aunque brindan una muestra amplia y representativa.

Los casos observados han sido distribuidos en cinco grandes grupos: 1. Grupos o Formas Protoasociativas; 2. Asociaciones simples o primarias; 3. Sociedades Comerciales; 4. Redes de Asociaciones y Empresas; 5. Redes Asociativas Complejas Público/Privadas. Los tres primeros tipos refieren a asociaciones u organizaciones en forma individual, mientras que los dos últimos a redes de asociaciones u organizaciones. Los criterios tomados en cuenta para definir estos tipos ideales han sido: a) el grado de complejidad organizacional expresado en la forma jurídica adoptada, la división de roles y jerarquías internas, y la correspondencia del tipo de forma jurídica adoptada en función de la actividad comercial y de agregado de valor de la AEAF, y b) la naturaleza de los actores sociales que integran las redes de colaboración (privado o público).

1. Grupos o formas proto-asociativas: asociaciones que no registran formalidad jurídica alguna en su organización, como la gran mayoría de los grupos constituidos con el fin de recibir la asistencia técnica, capacitación y financiamiento de los programas de desarrollo y que pueden compartir algunos bienes 0 actividades. Esta es la forma más simple de asociación y probablemente la más extendida en la actualidad entre los pequeños productores rurales en función de ser una condición constitutiva 0 de acceso a los beneficios de los diferentes programas de asistencia y desarrollo existentes -tanto públicos como privados-. Esta forma primaria posibilita el acceso a determinadas contribuciones -financieras, técnicas y de capacitación- que significan una mejora puntual o coyuntural en la satisfacción de ciertas necesidades o mejora en las condiciones de vida de sus integrantes y, en el mejor de los casos, inoculan el germen o fermento para emprender acciones colectivas con objetivos más ambiciosos y un proceso de organización de mayor formalidad y complejidad. 
Numerosos casos de este tipo pueden observarse en el marco de los ya mencionados programas de desarrollo donde los productores y pobladores rurales por propia iniciativa o a instancias de un técnico o profesional, deciden la constitución del grupo -condición base- para generar un proyecto que posibilite el acceso a subsidios o financiamiento, independientemente de la posibilidad de consolidarse como tal a partir de un objetivo o proyecto colectivo que trascienda la solución de necesidades individuales o prediales de cada uno de los integrantes en forma más o menos inmediata.

Por lo general la actividad en común no suele superar la adquisición de bienes que posibilita el acceso al beneficio -compra de insumos o equipamiento- que habitualmente se incorpora a cada predio, o se realiza una experiencia puntual y sin continuidad de comercialización en común de un porcentaje reducido de la producción; en ambos casos sin continuidad más allá de la operatoria que ha posibilitado el acceso a los beneficios de los programas.

No obstante, se debe tener en cuenta el proceso iniciado por estas motivaciones, donde una vez conformados los grupos se los promueve a elegir representantes y se fomenta el intercambio e interacción con otros grupos, suele llevar a emprender desafíos de mayor envergadura: gestión de infraestructura comunitaria, planteo de los problemas de tenencia y de ocupación de tierras como puesteros en lotes fiscales y privados, etc. En otras palabras, el proceso se inicia como instrumental y coyuntural para el acceso a un beneficio específico, pero puede madurar y escalar en la organización para abordar nuevas situaciones colectivas en beneficio del conjunto, las que desde una perspectiva dinámica y de largo plazo no pueden evaluarse sólo desde el grado de formalización jurídica alcanzado o el volumen de comercialización de su producción en forma conjunta.

Algunas iniciativas, ${ }^{22}$ que deberán ser analizadas con mayor profundidad, muestran que, a pesar del nivel inicial y de la escasa formalización de los grupos, éstos se encuentran en procesos de consolidación como AEAF mediante el apoyo de mediadores institucionales para mejorar aspectos productivos e implementar estrategias comerciales más eficientes y de mayor inserción y capacidad de negociación. Para ello requieren disponer de cierto volumen y calidad del producto, y regularidad en su provisión que sólo pueden alcanzar a través de la coordinación de sus acciones, y un apoyo continuado de los técnicos, las agencias y los programas de desarrollo.

2. Asociaciones simples o primarias: asociaciones que han pasado por un estadio proto-asociativo previo o que desde su génesis han formalizado su espíritu societario en alguna forma jurídica básica, aunque no necesariamente la más adecuada para los fines económicos y de agregado de valor.

22.- Pecaneros del Corredor Río Uruguay (Entre Ríos); Tejedoras de Susques (Jujuy); Productores de Damascos de San Rafael (Mendoza); Patagonia Cherry Group (Río Negro y Neuquén); Grupo asociativo Carnes Diferenciadas (Buenos Aires), (IICA, 2011). 
Nos referimos fundamentalmente a la constitución de asociaciones civiles y sociedades de hecho que se han generalizado en los programas de desarrollo rural a partir de los grupos reunidos para acceder a los beneficios de los programas. En muchos casos las sociedades de hecho y actividades comunes no se dan entre todos los miembros de un mismo grupo sino entre algunos miembros de diferentes grupos, lo cual indica que predominan las relaciones diádicas y ego-centradas que trascienden los límites de los grupos constituidos por los programas en sus estrategias de intervención.

En el marco del programa Cambio Rural, un relevamiento sobre 2000 productores realizado por INTA sostiene que el uso compartido de maquinaria era una actividad asociativa practicada para esa época por 1622 productores reunidos en grupos 0 asociaciones que integraban entre 2 a 42 productores cada uno. En la mayoría de los casos la formalización de estas asociaciones se realizaba a través de sociedades de hecho abarcando actividades agrícolas, ganaderas, horticultura, floricultura, entre otras (De Lisio, 1997:27-28).

Si bien hay preeminencia de grupos que se asocian para utilizar equipamiento, adquisición de insumos y producción en acciones conjuntas, también hay experiencias de agregado de valor abarcando algunas acciones de comercialización conjunta de parte de la producción, o la adquisición y uso conjunto de equipamiento para la transformación de su producción primaria. ${ }^{23}$ En el caso de la apicultura, la posibilidad de adquirir las cámaras de extracción de miel ha sido en muchos casos un disparador importante para nuclear a numerosos productores en asociaciones (CIET, 2007).

3. Sociedades comerciales: estas asociaciones de productores son aquellas que adoptan formas jurídicas adecuadas a los requerimientos comerciales o de transformación que actualmente habilita el marco jurídico del país. Son poco extendidas entre los pequeños productores y la población rural vulnerable, y las experiencias existentes se encuentran transitadas por los segmentos más capitalizados que integran el heterogéneo mundo de la agricultura familiar. Por sus características son aquellas que pueden participar plenamente de las relaciones de mercado y acceder sin intermediarios 0 mediadores institucionales a redes de colaboración con empresas privadas, sean estas de carácter comercial o cooperativo.

Un ejemplo es el caso de Unión del Norte SRL de Villa Ocampo (Santa Fe), donde 9 productores asociados a partir del Programa Cambio Rural en el año 1993, en una situación de crisis de ingresos, buscaron nuevas alternativas de trabajo conjunto constituyendo una Sociedad de Responsabilidad Limitada con el objeto de producción y comercialización de pollos. No tienen asalariados y comparten trabajo y capital (IICA, 2011).

23.- Cámara de Productores de Hongos de la provincia de Buenos Aires (Buenos Aires); Aromáticas del Alto Valle (Río Negro); Asociación de Productores 12 de agosto (Mendoza); Asociación de Agricultores de Juella (Jujuy); numerosas asociaciones apícolas (IICA, 2011). 
4. Redes de asociaciones y empresas: este nivel significa un cambio de naturaleza en el asociacionismo rural que se ha analizado hasta aquí, ya que no se trata de la integración de un grupo sino de las vinculaciones y relaciones de colaboración entre los productores y sus asociaciones con empresas comerciales 0 agroindustriales en el marco de una cadena productiva 0 de valor. También aquí las experiencias se caracterizan por un alto grado de excepcionalidad tanto respecto del número detectado como del grado de formalización y persistencia en el tiempo de las mismas. Su integración puede incluir desde grupos de productores con escasa conectividad grupal hasta asociaciones de productores con diferente grado de formalización jurídica, en relación directa con otros eslabones de la cadena que actúan como nodos centrales u organizadores y entre los que se destaca una gran asimetría estructural, económica y de poder de negociación. En estos casos, difícilmente los productores 0 sus asociaciones puedan otorgar mayor valor agregado a su producción que el acondicionamiento 0 empaque, el enfriamiento o congelado del producto, o procedimientos que garantizan cierta diferenciación -denominaciones o certificaciones- aunque mejoren sus condiciones de acceso a información, insumos, capacitación productiva, y mayor seguridad de colocación de su producción primaria. Las empresas a las que se encuentran vinculadas -sean estas cooperativas o sociedades comercialessuelen reservar para sí las etapas más complejas de transformación y comercialización de la producción. Veamos a continuación algunos ejemplos:

a) Contratos de producción entre empresas y productores: los mecanismos de contratación o coordinación vertical tienden a expandirse en la medida que aumentan las exigencias de identificación, diferenciación, calidad y regularidad de provisión de los productos. Este tipo de situaciones pueden observarse en la vitivinicultura tanto entre empresas bodegueras y cooperativas con grupos de productores individuales, como también en la industria cervecera entre las empresas elaboradoras y los productores de cebada y lúpulo. ${ }^{24}$ En estos casos si bien las relaciones entre el productor primario y la agroindustria se rigen en su inmensa mayoría por contratos verbales, también existen acuerdos contractuales a partir de los cuales las empresas tratan de garantizar tanto el volumen de entrega como fundamentalmente la calidad del producto, lo cual implica en muchos casos la provisión de insumos específicos, asesoramiento técnico y supervisión continua del proceso productivo. ${ }^{25}$

Como demuestran Bernet et al. (2002), la literatura académica y la mayoría de las experiencias conocidas indican que las grandes agroindustrias prefieren integrar más a productores grandes que a pequeños. Esto se debe a que disminuyen los costos de transacción al reducir costos en el acceso a los predios y el seguimiento de las actividades necesarias para garantizar las condiciones del producto. De esta forma obtienen una mayor seguridad en el cumplimiento de los requisitos tecnológicos dada la mayor disponibilidad de recursos que tienen estos productores, y estabilidad en la relación comercial de largo plazo por su mayor capacidad para asumir riesgos y los resultados de años nega-

24.- Para el tema de las relaciones contractuales en el sector vitivinícola puede consultarse entre otros: Bocco (2003) y Gutman (2005).

25.- En un estudio de 64 casos en 13 países de Latinoamérica realizado por la CEPAL a mediados de la década de 1990 se detectó que, con la excepción de Chile, existían muy pocas relaciones contractuales espontáneas entre pequeños productores y agro-negocios importantes. En el resto de los países casi siempre intervenía alguna organización gubernamental o no gubernamental que se hizo cargo de los costos de transacción, de fomentar la organización de los productores, de su administración y contabilidad, de la capacitación y de la negociación (Dirven, 2001:26). 


\section{LAS FORMAS ASOCIATIVAS DE LA AGRICULTURA FAMILIAR EN EL DESARROLLO RURAL ARGENTINO DE LAS ÚLTIMAS DÉCADAS (1990-2014)}

tivos. Las contrataciones con pequeños productores en forma individual suele ser una "solución de emergencia" cuando no hay suficientes productores grandes que abastezcan las plantas de procesamiento. No obstante, también existen experiencias internacionales que demuestran lo contrario dado los menores costos y mayor productividad de los pequeños productores. ${ }^{26}$

b) Los contratos de colaboración empresarial: ya sea como Asociaciones de Colaboración Empresaria (ACE) para aprovechar ciertos bienes o servicios que facilita la actividad empresarial del conjunto de sus miembros -acceso y disponibilidad de equipamiento o tecnología- o más propiamente como Unión Transitoria de Empresas (UTE) para participar en el aprovisionamiento de un mercado específico que en forma individual es imposible de satisfacer. Estas formas se encuentran poco extendidas en la agricultura familiar en correlación directa al bajo grado de sociedades comerciales que servirían para generar estas alianzas de colaboración empresaria. ${ }^{27}$

c) Alianzas estratégicas entre empresas de industrialización y asociaciones de productores: como se mencionara anteriormente, las agroindustrias prefieren establecer sus vinculaciones con grandes productores en lugar de numerosos pequeños productores en forma individual debido a los menores costos de transacción. No obstante, aunque existen relativamente pocas experiencias, ${ }^{28}$ éste es un tema que puede ser resuelto a partir de las asociaciones de productores en la medida que pueden integrarlos, organizarlos, facilitar las tareas de capacitación y asistencia técnica por sí mismas, como intermediarios de la agroindustria o por su vinculación con las agencias de desarrollo, así como abordar tareas previas de clasificación, calidad, acondicionamiento y empaque. De este modo, las asociaciones de productores permiten remover los principales obstáculos que suelen encontrar los pequeños productores para su integración vertical con grandes industrias transformadoras, como lo demuestran algunas experiencias internacionales. ${ }^{29}$

d) Clusters: 0 agrupamientos territoriales de empresas alrededor de determinados segmentos productivos relevantes, son considerados agentes claves del desarrollo local por aquellas corrientes de pensamiento que sostienen que la competitividad ya no se asienta en forma agregada en países, sec-

26.- Key y Runsten (citado por Bernet et al., 2002) describen un caso en México en el cual una empresa contrató exitosamente a docenas de pequeños proveedores para la producción de brócoli y coliflor para exportación. Cálculos previos de la empresa demostraron que producir estas hortalizas en los huertos de los pequeños productores era un $55 \%$ más barato y su rendimiento por hectárea más alto que el que obtenía en forma directa la empresa.

27.- Como ejemplo podemos citar el caso del Grupo Gea-San Carlos que es un grupo de tamberos de la localidad de San Carlos, provincia de Santa Fe, que se asocia con el objetivo de compartir información técnica, comprar maquinaria de uso comunitario e insumos en forma conjunta. A ello se agrega la comercialización conjunta de su producción a partir de concursos de precios y condiciones donde participan como demandantes las usinas lácteas de la zona (IPAC, 1997).

28.- Por ejemplo, la Asociación de Productores Orgánicos de la Cuenca del Pichanas (APOCUP) de la provincia de Córdoba provee materia prima (aceitunas) a la empresa Paso Viejo en el marco del plan piloto "Polo de reconversión olivícola al sistema orgánico Cuenca del Pichanas" promovido por la ex Secretaría de Agricultura de la Nación en el año 1999 (IICA, 2011). Este caso podría ser incluido como tipo 3.6. de esta tipología si las agencias públicas mantienen su participación como mediadores en el tiempo más allá de la gestación del acuerdo inicial.

29.- Örnberg (1999) pone énfasis en la importancia de las asociaciones de productores en Tailandia como punto de partida para la producción de papa bajo contrato con grandes empresas de procesamiento de este producto en la década de 1980. Estas asociaciones surgieron en los años ' 60 para acceder a los beneficios de un plan de gobierno que les proveía de semilla de alta calidad sólo a miembros oficiales de una asociación. La existencia facilitó a las empresas ahorrar costos de transacción en el acopio de los volúmenes requeridos de papa, mientras que los productores aprovecharon para tener un mercado seguro para su producto.

CIRIEC-España, Revista de Economía Pública, Social y Cooperativa 
tores o en empresas aisladas, sino en los territorios y las redes construidas alrededor de los agrupamientos de empresas que se asientan en los mismos (Alburquerque, 2003:22). Estos clusters compuestos por establecimientos de la agricultura familiar, microempresas y empresas de diversas dimensiones que participan en diferentes eslabones de una cadena de valor, se plantean una estrategia de mediano y largo plazo a partir del trabajo asociativo para la elaboración de un diagnóstico de situación, definición de estrategias de mejoramiento y capacitación en beneficio de cada uno de los eslabones y el conjunto de la cadena. La cadena de valor se define como una red estratégica de organizaciones -empresas independientes, productores, procesadores y distribuidores- que reconocen la necesidad de colaborar para identificar objetivos estratégicos, es decir, invertir y compartir riesgos, beneficios, tiempo, energía y recursos, en favor de cada una de las partes que la integran. ${ }^{30}$

5. Redes asociativas complejas público/privadas: estas construcciones institucionales con diferentes grados de formalización y desarrollo también son excepcionales, pero cuando son exitosas tienen un gran impacto local y/o regional. En todos los casos, entre las asociaciones de productores y el mercado y sus agentes, existen mediadores institucionales que participan de algún modo en la organización 0 asesoramiento de los productores. Estos mediadores pueden ser públicos -agencias y programas de desarrollo, municipios, etc.- 0 de la sociedad civil -ONGs-, y en muchos casos participan en forma conjunta.

Habitualmente la comuna o alguna agencia o programa estatal, con la colaboración de ONGs u asociaciones de carácter generalista y reivindicativo, actúan como referente organizador del sistema en el que se articulan productores y pobladores rurales, asociaciones y empresas privadas para la conformación de redes de colaboración en la comercialización, transformación y distribución de la producción. Estas experiencias pueden ser puntuales o coyunturales sin llegar a permanecer en el tiempo 0 , en cambio, consolidarse y generar una experiencia que, en ocasiones, se replica con diferentes niveles de escala, organización y expansión territorial. Veamos a continuación algunos subtipos:

a) Alianzas entre asociaciones de la sociedad civil y asociaciones de la agricultura familiar. en estos casos los programas de desarrollo o agencias estatales promueven la vinculación de los grupos de beneficiarios con asociaciones pre-existentes que pueden actuar como organizadores, concentradores o eslabón superior para la transformación y comercialización de la producción de las AEAF.31

30.- El caso del Cluster Avícola Paraná es una experiencia relevante en este sentido, integrado por 19 micro y medianas empresas ubicadas en las localidades de Concepción del Uruguay, Racedo, Crespo, Gualeguay, Villaguay, Hernandarias y Paraná (provincia de Entre Ríos), dedicadas a la producción de pollos y huevos, una empresa frigoríica y de cocido de aves, y una empresa que industrializa huevo líquido y en polvo (IICA, 2011).

31.- El Proyecto de Desarrollo Rural de las Provincias del Noreste Argentino (PRODERNEA) a través de la articulación con la Asociación Cooperadora del Proyecto de Apoyo a Egresados del Centro Educativo de Nivel Medio N 2 para Comunidades Autóctonas y Sectores Marginales, una asociación civil pre-existente identificada con la sigla PROPAE, ha posibilitado a las comunidades aborígenes del Oeste formoseño habilitar un sistema de extracción, acopio, fraccionamiento y comercialización de miel que les permitió pasar de simples recolectores a productores y aumentar sensiblemente el número de personas dedicadas a la actividad así como el volumen de negocio e ingresos. No obstante uno de los principales problemas que continúa sin resolver para la proyección de estas asociaciones en las comunidades aborígenes consiste en la ausencia de una figura jurídica adecuada que les permita mejorar su inserción en la comercialización (CIET, 2007). 


\section{LAS FORMAS ASOCIATIVAS DE LA AGRICULTURA FAMILIAR EN EL DESARROLLO RURAL ARGENTINO DE LAS ÚLTIMAS DÉCADAS (1990-2014)}

b) Acuerdos contractuales e integración con grandes industrias y cadenas de comercialización: el Estado municipal o alguna agencia estatal a cargo de programas de desarrollo organiza y gestiona la vinculación de los grupos de productores 0 asociaciones con grandes empresas transformadoras o cadenas de distribución o supermercados con el objeto de habilitar canales de comercialización de su producción a un mercado que trascienda el ámbito local. 32

c) Participación en la organización de mercados: existen experiencias de municipios y las agencias estatales a cargo de programas de desarrollo que promueven y gestionan la organización de mercados donde los grupos de productores y sus asociaciones participan y, de ese modo, reducen la dependencia tradicional de los intermediarios accediendo a mercados más amplios. Esto incluye desde la organización de sistemas de coordinación que posibilitan acceder a una mejor información y negociación conjunta de precios en mercados concentradores y remates ferias, 33 y otros que alcanzan una alta formalización organizativa y territorial como las ferias francas. ${ }^{34}$

\section{5.- Reflexiones finales}

El desarrollo rural tiene como condición el desarrollo económico de los territorios; esto requiere de la presencia de capital social. Un indicador frecuentemente mencionado en la literatura como expresión del capital social y las capacidades de desarrollo de los territorios es la existencia de un número considerable y diverso de asociaciones, pero este requisito es insuficiente si no existen ciertas condiciones complementarias que caracterizan las relaciones sobre los que se fundan las asociaciones, sus objetivos y las acciones que efectivamente llevan adelante.

32.- Experiencias en este sentido han sido llevadas a cabo por el municipio de Lavalle en la provincia de Mendoza para la vinculación de un pequeño grupo de medieros hortícolas, productores de alcauciles, con una agroindustria extraterritorial; y por el INTA de la misma zona para productores de tomate. Los organismos públicos actuaron como mediadores en esta relación que se formalizó a través de contratos. Además el municipio de Lavalle junto a una ONG. local han promovido la constitución del grupo de mujeres envasadoras de conservas, dulces y salsas, cuyos excedentes se comercializaron en los mercados de Mar del Plata y Buenos Aires a través de la cadena de Supermercados Coto a partir de las gestiones realizadas por el municipio. (Bocco et al., 2008, IICA, 2011).

33.- Distintas experiencias han sido realizadas exitosamente en este sentido: los remates-feria para pequeños productores ganaderos organizados por la Municipalidad de Mercedes (provincia de Corrientes) y el INTA con el apoyo del PRODERNEA; y la venta de los productos hortícolas en el mercado concentrador de Corrientes, a partir de una logística organizada por el INTA y la provincia en el marco del Proyecto Mercado (PROMER) del mismo programa (FIDA, 2013).

34.- El caso de las ferias francas en Misiones es el más importante en este sentido. Fue impulsada en 1995 por el Movimiento Agrario Misionero (MAM) conjuntamente con los programas de desarrollo rural que trabajaban en la zona (PSA, Prohuerta y Cambio Rural) y el municipio de la ciudad de Oberá. La feria se constituyó inicialmente como una asociación civil sin fines de lucro que posibilitaba la venta del excedente de los pequeños productores directamente a los consumidores y en una década creció hasta alcanzar 70 feriantes en su sede original y más de 40 ferias con la participación de alrededor de 2.000 productores en la Provincia. En 1998 se crea la Asociación de Ferias Francas de Misiones y posteriormente, experiencias similares en otras provincias argentinas (Corrientes, Salta; San Juan, Santa Fe, Entre Ríos, Chaco y Catamarca), posibilitaron la fundación de la Organización Nacional de las Ferias Francas (IICA, 2011). En un estudio reciente sobre las ferias de la agricultura familiar en Argentina (Golsberg, 2010), se registraron 144 ferias de este tipo en todo el país.

CIRIEC-España, Revista de Economía Pública, Social y Cooperativa 
Las experiencias demuestran que las condiciones para que las asociaciones constituyan efectivamente un capital social, que contribuya al desarrollo de los territorios, no están dadas ni son extendidas sino, por el contrario, son escasas y requieren ser construidas. La posibilidad de identificarlas requiere de un análisis en profundidad de experiencias concretas en contextos determinados.

Las Asociaciones Económicas de la Agricultura Familiar no constituyen el único tipo de asociaciones que integran el capital social de una comunidad, pero reúnen teóricamente junto a otras asociaciones económicas como las cooperativas y reivindicativas -gremios 0 sindicatos ruralescondiciones favorables para transformarse en agentes de desarrollo por su naturaleza y objetivos, aun teniendo en cuenta el carácter competitivo que puedan asumir.

Las experiencias observadas sugieren que, a pesar de la progresiva disminución de la población rural y del número de establecimientos de pequeños y medianos productores agropecuarios, en Argentina se ha incrementado el pluralismo asociativo. El proceso desarrollado ha sido fructífero respecto de la conformación de grupos que han recibido capacitación, asistencia técnica, financiamiento y fortalecimiento organizacional por parte de programas gubernamentales; también lo ha sido en el número de asociaciones de todo tipo con amplia dispersión territorial que fueron progresivamente organizándose y aun integrándose en redes de organizaciones -como el FoNAFy otras-, pero resulta menos exitoso en cuanto al número de grupos que formalizan su acción colectiva en una organización económica de carácter formal que se consolidan con cierta autonomía y capacidad para desempeñarse con relativa eficiencia frente al mercado o el Estado.

El grado de formalización de las AEAF que hemos intentado identificar y definir se expresa en un abanico amplio de posibilidades empíricas que van desde aquellas situaciones asociativas de grado informal o inicial donde los vínculos son más laxos y las estructuras flexibles, con pocos objetivos 0 enfocados a una meta puntual, hasta aquellas estructuradas por normas jurídicas, funciones estables y jerarquización interna, habitualmente de mayor antigüedad y envergadura; así como por diferentes grados de vinculaciones y alianzas de relativa perdurabilidad con otros actores económicos, sociales y políticos.

Más allá del grado de formalización alcanzado por las nuevas asociaciones, especialmente las de naturaleza económica promovidas por los programas de desarrollo rural, cabe señalar que las mismas han posibilitado a muchos productores -e incluso a población rural no agraria- encontrar alternativas de ingresos a partir de diversificar sus actividades económicas al actuar como medios -buffers, en los términos planteados por Darnhofer et al. (2008)- que otorgan a sectores vulnerables de la población rural opciones complementarias de ingresos y disminución del nivel de riesgo que tenían al depender de una única actividad laboral o productiva. Por ello, la actividad de estas asociaciones no se despliega sólo en el espacio económico del mercado, sino simultáneamente en la esfera política y social. 
Independientemente del grado de consolidación alcanzado por las asociaciones, debe considerarse que estos procesos asociativos en sectores tradicionalmente aislados y altamente vulnerables de la estructura social rural, han generado posibilidades de acceso a información, capacitación, asistencia técnica por el sólo hecho de constituir el grupo asociativo y se constituyeron en una contribución sustancial a la mejora de la calidad de vida de las comunidades, cuyos resultados no pueden medirse exclusivamente por el éxito de sus asociaciones económicas. En muchos casos, estas primeras e incipientes forma de asociación han posibilitado mejoras en sus predios y en la vida de las pequeñas comunidades donde residen -pozos de agua, obras de infraestructura en la comunidad, accesos, etc.-, aunque las experiencias no hayan madurado en organizaciones económicas consolidadas, autónomas y con proyección comercial o agroindustrial. Teniendo en cuenta la situación de partida de sus integrantes, los resultados alcanzados no pueden considerarse de menor importancia.

También, a pesar de ello, existen experiencias destacadas, pocas en términos relativos al número de grupos beneficiarios, cuya organización les ha posibilitado llegar a mercados nacionales e internacionales. En casos excepcionales se han logrado ciertas articulaciones en redes y agrupamientos inter-asociaciones como los consorcios, clústers, ferias francas y convenios con agroindustrias, redes de supermercados y cooperativas. En estos casos de mayor complejidad, se expresa con claridad la presencia y acompañamiento de instituciones y agencias estatales que participan activamente en su organización, direccionamiento y continuidad de la experiencia a partir de la asistencia técnica, organizacional y comercial.

El desafío en el mediano plazo radica en mejorar la tasa de supervivencia y consolidación de estas asociaciones haciendo más eficiente la relación cantidad/calidad que permita trascender de las experiencias aisladas de resultado positivo para sus integrantes en un capital social comunitario que contribuya a la construcción del desarrollo de los territorios. Para ello es necesario conocer en profundidad los procesos que han atravesado las experiencias consideradas exitosas, rescatar sus enseñanzas para transmitirlas y replicarlas, y avanzar en reformas de las reglas de juego y de los instrumentos de promoción que posibiliten un mayor grado de formalización de estas iniciativas multiplicando el número de casos que alcancen un estadio de consolidación que les otorgue relativa autonomía y eficiencia para desempeñarse ante el mercado, la sociedad y el propio Estado. 


\section{6.- Bibliografía}

ALBURQUERQUE, F. (2003): "Teoría y práctica del enfoque del desarrollo local". En: Consultoría de capacitación promovida por la Unión Europea sobre "Desarrollo territorial y gestión del territorio", La Serena (Chile).

BALSA, J. (2006): El desvanecimiento del mundo chacarero. Transformaciones sociales de la agricultura bonaerense: 1937-1988, Universidad Nacional de Quilmes, Bernal.

BANCO MUNDIAL (2007): Los Pobres Invisibles. Un panorama de la pobreza rural en la Argentina, Informe № 39947-AR, Banco Mundial, Región América Latina y el Caribe, Buenos Aires.

BANCO MUNDIAL (2001): ¿Qué es el Capital Social?, Banco Mundial, Washington. Disponible en http://www.worldbank.org/poverty/spanish/scapital/index.htm..

BAUDRÓN, S. (1993): "Programa de crédito y apoyo técnico para pequeños productores del noroeste argentino". En: Flores, G. (Comp.), De agricultor a pequeño empresario con crédito agrícola. Experiencias y procesos futuros, PROCEDER, INDAP, IICA, Santiago de Chile, 77-84.

BERNET, T., LARA, M., URDAY, P. \& DEVAUX, A. (2002): "El Reto de Vincular a los Pequeños Productores de Papa con la Agroindustria", Revista Latinoamericana de la Papa, 13, 1-23.

BID (2001): Iniciativa Interamericana de Capital Social, Ética y desarrollo, Banco Interamericano de Desarrollo (BID). Disponible en http://www.iadb.org/etica/iniciativa.cfm.

BID \& PNUD (2000): Índice de desarrollo de la sociedad civil de Argentina, Banco Interamericano de Desarrollo (BID) y Programa de las Naciones Unidas para el Desarrollo (PNUD), Edilab, Buenos Aires.

BOCCO, A. (2003): Reestructuración vitivinícola, integración agro-industrial y nuevas relaciones entre las bodegas y los productores de uvas finas, CIEL-CONICET, Programa Interdisciplinario de Estudios Agrarios, Buenos Aires.

BOCCO, A., ALTURRIA, L., ANTONIOLLI, E. \& DUBII, D. (2008): "Análisis participativo del proceso de transformación productiva e institucional en el departamento de Lavalle, Provincia de Mendoza". En: Schajtman, A. \& Barsky, O. (Comps.), El desarrollo rural en la argentina. Un enfoque territorial, Siglo XXI, Buenos Aires.

BOUCHER, F. \& RIVEROS, H. (1995): La Agroindustria Rural en América Latina y el Caribe. Su entorno, marco conceptual e impacto, PRODAR-IICA, San José de Costa Rica.

BOURDIEU, P. (1980): "Le capital social. Notes provisoires", Actes de la Recherche en Sciencies Sociales, 3, 2-3. 
CEDES (2007): Diagnóstico sobre la contribución del PRODERNEA al capital social de los actores, sus organizaciones y comunidades, Centro de Estudios de Estado y Sociedad (CEDES), Buenos Aires.

CENDA (2010): La anatomía del nuevo patrón de crecimiento y la encrucijada actual. La economía argentina en el período 2002-2010, Centro de Estudios para el Desarrollo Argentino (CENDA), Cara o Ceca, Buenos Aires.

CIET (2007): Sistematización de la experiencia e intervención del PRODERNEA en la producción apícola en la Provincia de Formosa, Centro Interdisciplinario de Estudios Territoriales (CIET), Resistencia.

COLEMAN, J. (2000): Social capital in the creation of human capital. Social capital. A multi-faceted perspective, World Bank, Washington.

COWAN ROS, C. (2010): "De la producción del capital social a la proyección de las luchas simbólicas en el territorio. Estudio de caso de la Puna y Quebrada de Humahuaca". En: Manzanal, M., Arceno, M. \& Nussbaumer, B. (Comps.), Territorios en construcción. Actores, tramas y gobiernos, entre la cooperación y el conflicto, Ciccus, Buenos Aires, 225-253.

DARNHOFER, I., BELLON, S., DEDIEU, B. \& MILESTAD, R. (2008): "Adaptive farming Systems. A position paper". En: WS 3: Adaptive farming systems, $8^{\text {th }}$ European IFSA Symposium, ClermontFerrand (France).

DE LISIO, C. (1997): "Ciudadanos en la Economía y emprendedores en la sociedad". En: Formas Asociativas. Reconversión y crecimiento, Instituto de Provincial de Acción Cooperativa (IPAC), Ministerio de la Producción y el Empleo de la Provincia de Buenos Aires, La Plata, 15-35.

DIRVEN, M. (2001): Entre el ideario y la realidad: capital social y desarrollo agrícola -algunos apuntes para la reflexión-, División de Desarrollo Productivo y Empresarial, CEPAL, Santiago de Chile.

DURSTON, J. (2001a): "El capital social en seis comunidades campesinas de Chile: adelantos y desafíos de una investigación en marcha". En: Durston, J. \& Miranda, F. (Comps.), Capital social y políticas públicas en Chile. Investigaciones recientes, CEPAL, Santiago de Chile, 39-65.

DURSTON, J. (2001b): "Evaluando capital social en comunidades campesinas en Chile”, Presentación realizada ante Fundación Ford, Santiago de Chile, 19 de diciembre.

ELGUE, M. \& CHIARADÍA, C.A. (2007): Formas asociativas para la Agricultura Familiar: elementos para el análisis funcional normativo de las distintas formas jurídicas, PRODERNEA-PRODERNOA, SAGPyA, Buenos Aires.

FIDA (2013): El Fondo Internacional de Desarrollo Agrícola en los países de ingresos medios: el caso argentino, Fondo Internacional para el Desarrollo Agrícola (FIDA), Buenos Aires.

FIDA (2010): Evaluación del Programa en el país, Informe № 2223-AR, Fondo Internacional para el Desarrollo Agrícola (FIDA)-República Argentina, Buenos Aires. 
FORMENTO, S. (1994): Formas Asociativas para la Empresa Agropecuaria. Aspectos Impositivos y Legales, Programa Cambio Rural, Área de Trabajo en Formas Asociativas, INTA, Buenos Aires.

GAIGER, L. I. (2004): "Emprendimiento económicos solidarios", En: Cattani, A.D., La otra economía, Altamira, Buenos Aires, 229-241.

GOLSBERG, C. (2010): Agricultura familiar: ferias de la agricultura familiar en Argentina, INTA, Buenos Aires.

GUTMAN, G. (2005): Agricultura de contrato de Pequeños Productores Agropecuarios con agroindustrias y/o Agrocomercios en Argentina. Experiencias, lecciones, lineamientos de políticas, SAGPyA, Buenos Aires.

IAZZETTA, O. (2005): "El gobierno de Kirchner y los desafíos democráticos pendientes", Temas y Debates, 10, 35-55.

IICA (2011): Formas asociativas no cooperativas en el agro. Hacia una estrategia de investigación, Instituto Interamericano de Cooperación Agrícola (IICA), Buenos Aires.

INDEC (2012): Encuesta Permanente de Hogares, Instituto Nacional de Estadísticas y Censos (INDEC), Buenos Aires.

INDEC (2010): Censo Nacional de Población y Vivienda 2010, (datos provisorios), Instituto Nacional de Estadísticas y Censos (INDEC), Buenos Aires.

INDEC (1988): Censo Nacional Agropecuario 1988, Instituto Nacional de Estadísticas y Censos (INDEC), Buenos Aires.

INDEC (2002): Censo Nacional Agropecuario 2002, Instituto Nacional de Estadísticas y Censos (INDEC), Buenos Aires.

INTA (2010): Las estrategias del PROFEDER para el apoyo del desarrollo territorial. Estrategias y experiencias para el trabajo de extensión, Coordinación Nacional de Transferencia y Extensión, Instituto Nacional de Tecnología Agropecuaria (INTA), Buenos Aires, Disponible en: http://agro.unc.edu.ar/ extrural/Gargicevich.pdf.

IPAC (1997): Formas Asociativas. Reconversión y crecimiento, Instituto de Provincial de Acción Cooperativa (IPAC), Ministerio de la Producción y el Empleo de la Provincia de Buenos Aires, La Plata.

LATTUADA, M. (2006): Acción colectiva y corporaciones agrarias en la Argentina. Transformaciones institucionales a fines del siglo XX, Universidad Nacional de Quilmes, Bernal.

LATTUADA, M. (2000): Cambio rural. Política y desarrollo en la argentina de los '90, CED-Acasur Editorial, Buenos Aires.

LATTUADA, M., MÁRQUEZ, S. \& NEME, J. (2012): Desarrollo Rural y Política. Reflexiones sobre la experiencia argentina desde una perspectiva de gestión, Ciccus, Buenos Aires. 
LATTUADA, M., NOGUEIRA, M. E., RENOLD, J. M. \& URCOLA, M. (2011): Cooperativismo y capital social en la agricultura argentina a comienzos del siglo XXI, PROSAP, Buenos Aires.

LIN, N. (2001): Social capital: theory of social structure and action, Cambridge University Press, Cambridge.

MÁRQUEZ, S. (2007): Un año del Foro. Crónica, realizaciones y perspectivas del ejercicio del diálogo político desarrollado por el Foro Nacional de la Agricultura Familiar, PROINDER, Buenos Aires.

MINISTERIO DE ECONOMÍA DE LA NACIÓN ARGENTINA (2013): http://www.mecon.gov.ar/economica/basehome/dnper_complejos_exportadores.htm.

MOYANO ESTRADA, E. (2002): "Acción colectiva y organizaciones profesionales en la agricultura". En: Gómez Benito, C. (Ed.), Agricultura y Sociedad en el Cambio de Siglo, McGraw Hill Interamericana de España, Madrid, 567-594.

MOYANO ESTRADA, E. \& ENTRENA DURÁN, F. (2002): "Cooperativismo y representación de intereses en la agricultura española". En: Gómez Benito, (Ed.), Agricultura y Sociedad en el Cambio de Siglo, McGraw Hill Interamericana de España, Madrid, 595-622.

NEFFA, J.C. (2010): "Modelos productivos y sus impactos en la relación salarial. Reflexiones a partir del caso argentino". En: De La Garza Toledo, E. \& Neffa, J.C., Trabajo y modelos productivos en América Latina, CLACSO, Buenos Aires, 261-374.

NEIMAN, G., BERGER, M., ARROÑADE, S., FABIO, F., GOLDFARB, L., KAROL, A., MINGO, E. \& NEIMAN, M. (2006): "Diversidad de las formas de representación de intereses entre organizaciones de pequeños productores del agro argentino: base social, reivindicaciones y articulaciones". En: Manzanal, M., Neiman, G. \& Lattuada, M. (Comps.), Desarrollo rural. Organizaciones, instituciones y territorios, Ciccus, Buenos Aires, 177-210.

NOGUEIRA, M.E. \& URCOLA, M. (2013): "La jerarquización de la agricultura familiar en las políticas de desarrollo rural en Argentina y Brasil (1990-2011)", Revista IDeAS, Interfaces em Desenvolvimento, Agricultura e Sociedade, 7, 2, 96-137.

NORTH, D. (1995): Instituciones, cambio institucional y desempeño económico, Fondo de Cultura Económica, México.

NYSSENS, M. (1996): "Economie populaire au Sud, économie social au Nord: des germes èconomie solidaire?". En: Sauvage, P., Réconcilier l' economique et le social, OCDE, Paris.

OBSCHATKO, E., BASAÑES, C. \& MARTINI, G. (2011): Las Cooperativas Agropecuarias en la República Argentina: diagnóstico y propuestas, MAGyP-IICA, Buenos Aires.

OBSCHATKO, E. (2009): Las explotaciones agropecuarias familiares en la República Argentina. Un análisis a partir de los datos del Censo Nacional Agropecuario 2002, MAGyP-IICA, Buenos Aires.

OBSCHATKO, E. (1994): Efectos de la desregulación sobre la competitividad de la producción argentina, Grupo Editor Latinoamericano, Buenos Aires. 
ÖRNBERG, L. (1999): "Potato farmers' organization in Thailand: a discussion on the prerequisites of the formation and survival of farmer organizations". En: 7th International Conference on Thai Studies, Amsterdan.

PEÓN, C., ROSLER, A. \& AVARO, D. (1993): Estudios de Sociología Política: M. Weber, E. Durkheim y F. Tönnies, Centro Editor de América Latina, Buenos Aires.

PNUD (2000): Índice del informe sobre desarrollo humano en Chile 2000, Programa de Naciones Unidas para el Desarrollo (PNUD), Santiago de Chile.

PROINDER (2003): Los programas de desarrollo rural ejecutados en el ámbito de la SAGPyA, Proyecto de Desarrollo de Pequeños Productores Agropecuarios (PROINDER), Dirección de Desarrollo Agropecuario, Secretaría de Agricultura, Ganadería, Pesca y Alimentación (SAGPyA), Ministerio de Economía y Producción, Buenos Aires.

PUTMAN, R. (1993): Making Democracy work. Civic traditions in mordern Italy, Princeton University Press, Princeton.

SCHIAVONI, G. (2001): "Organizaciones agrarias y constitución de categorías sociales. Plantadores y campesinos en el nordeste de Misiones (Arg.)", Estudios Regionales 10, 20, 7-21.

TORT, M.I. \& LOMBARDO, P. (1994): Las formas asociativas como alternativa para apoyar la reconversión productiva, Programa Cambio Rural, INTA, Área de Trabajo en Formas Asociativas, Buenos Aires.

UCA (2011): Deudas y progresos sociales en un país que hace frente a su bicentenario. Argentina 2004-2010, Informe Especial del Observatorio de la Deuda Social, Universidad Católica Argentina (UCA), Buenos Aires.

WEBER, M. (1996): Economía y sociedad, Fondo de Cultura Económica, México.

WOOLCOCK, M. (1998): "Social capital and economic development. Toward a theoretical synthesis and policy framework", Theory and Society, 27, 151-208. 